\title{
The microstructure and mechanical properties of selectively laser melted AlSi10Mg: the effect of a conventional T6-like heat treatment
}

\author{
Nesma T. Aboulkhair ${ }^{\mathrm{a}, \mathrm{b} 1}$, Ian Maskery ${ }^{\mathrm{a}}$, Chris Tuck ${ }^{\mathrm{a}}$, Ian Ashcroft ${ }^{\mathrm{a}}$, and Nicola M. Everitt ${ }^{\mathrm{a}}$ \\ ${ }^{a}$ Additive Manufacturing and 3D Printing Research Group, Faculty of Engineering, University of \\ Nottingham, Nottingham NG7 2RD, United Kingdom \\ ${ }^{\mathrm{b}}$ Bioengineering Research Group, Faculty of Engineering, University of Nottingham, Nottingham NG7 \\ 2RD, United Kingdom
}

\begin{abstract}
Selective laser melting (SLM) of aluminium is of research interest because of its potential benefits to high value manufacturing applications in the aerospace and automotive industries. In order to demonstrate the credibility of SLM Al parts, their mechanical properties need to be studied. In this paper, the nano-, micro-, and macro-scale mechanical properties of SLM AlSi10Mg were examined. In addition, the effect of a conventional T6-like heat treatment was investigated and correlated to the generated microstructure. Nanoindentation showed uniform hardness within the SLM material. Significant spatial variation was observed after heat treatment due to phase transformation. It was found that the SLM material's microhardness exceeded its die-cast counterpart. Heat treatment softened the material, reducing micro-hardness from $125 \pm 1 \mathrm{HV}$ to $100 \pm 1 \mathrm{HV}$. An ultimate tensile strength (333 MPa), surpassing that of the die cast counterpart was achieved, which was slightly reduced by heat treatment (12\%) alongside a significant gain in strain-to-failure ( threefold). Significantly high compressive yield strength was recorded for the as-built material with the ability to withstand high compressive strains. The SLM characteristic microstructure yielded enhanced strength under loading, outperforming cast material. The use of a T6-like heat treatment procedure also modified the properties of the material to yield a potentially attractive compromise between the material's strength and ductility making it more suitable for a wider range of
\end{abstract}

\footnotetext{
${ }^{1}$ E-mail: nesma.aboulkhair@nottingham.ac.uk
} 
applications and opening up further opportunities for the additive manufacturing process and alloy combination.

Keywords: Additive manufacture; aluminium alloys; nanoindentation; tensile behaviour; compressive behaviour; heat treatment.

\section{INTRODUCTION}

Selective laser melting (SLM) is a layer-based additive manufacturing technology that is utilised to manufacture complex and customised structures from metal powder. The main advantage of this process over conventional manufacturing methods is the facility to create lightweight parts, such as those which result from topology optimisation [1, 2] or include lattice structures [3-5] to replace bulk solids. SLM saves resources, reduces waste and carbon footprint $[6,7]$. SLM also makes it possible to manufacture parts from materials that can be difficult to machine [8]; such as AlSi10Mg, which, due to the presence of the hard Si phase, is mainly used in casting.

Aluminium alloys are attracting the attention of SLM users because of their wide use across many industrial sectors; aerospace and automotive being two examples. However, processing $\mathrm{Al}$ alloys with SLM can be challenging because of the material's high reflectivity [9] and thermal conductivity [10], which can lead to high levels of porosity. There have been a number of previous studies concerned with parameter optimisation to produce close to fully dense parts from Al alloys using SLM, such as [11-16]. In addition, several studies have been dedicated to formulating the mechanisms of pore formation and developing means of porosity reduction, such as $[12,17]$. The use of high laser power (up to $1 \mathrm{~kW}$ ) was recommended by Buchbinder et al. [14], whereas Aboulkhair et al. [12] used a pre-sinter scan strategy (multiple scans per layer) to reduce porosity significantly (from $97.74 \%$ to $99.82 \%$ ) whilst using relatively low laser power.

The manufacture of load bearing parts using SLM is being considered in numerous applications and consequently, the mechanical performance of SLM parts is gaining further attention. SLM of Al alloys 
produces a characteristically fine microstructure [18] that has been shown to yield mechanical behaviour significantly different from that seen in conventionally cast material [19], which usually has a coarser microstructure. There are several aspects that require consideration when studying the mechanical behaviour of SLM parts. Although the effect of build orientation has been reported as influential on the tensile properties of Ti alloys [20], it has less influence in the case of AlSi10Mg; mainly affecting elongation under tensile loading [19, 21]. The energy density delivered to the material during processing also affects the mechanical properties. Various mechanical properties of SLM parts made from Al alloys have been reported in the literature, such as tensile behaviour [19, 22-24], micro-hardness [21, 23], impact resistance [21], and fatigue performance [22, 25]. Read et al. [19] showed that the tensile strength of SLM AlSi10Mg is higher than that of the die cast counterpart, but the latter has better ductility. Siddique et al. [22] investigated the effect of the energy density, build plate preheating, and post processing stress relief on the tensile properties of SLM AlSi12, reporting that the energy density had the strongest influence. Kempen et al. [21] reported a higher hardness for SLM AlSi10Mg when compared to the die-cast equivalent as well as improved impact resistance. The fatigue life of SLM Al alloys was found to be affected by porosity or the presence of un-bonded regions in the samples [22]. As for the compressive behaviour of SLM Al alloys, the attention has mainly been directed to studying the latticed structures [26], to the authors' knowledge, this study is the first to report on the compressive behaviour of solid SLM AlSi10Mg.

Altering the mechanical properties of SLM materials by heat treatment usually follows the procedures that have been developed for conventionally manufactured materials, with no special attention to the distinct microstructure that SLM produces. For example, Brandl et al. [25] enhanced the fatigue performance of SLM AlSi10Mg using a T6 heat treatment, a process including solution treatment, water quenching, and artificial ageing, which they referred to as "peak-hardening". Prashanth et al. [24] reported microstructure coarsening and material softening when annealing SLM AlSi12, which is the same response as conventionally cast material. Importantly, according to Aboulkhair et al. [27], a 
conventional T6 procedure resulted in the softening of SLM AlSi10Mg. This raises the question of the validity of conventional heat treatments when it comes to SLM materials, and what would be the effect of these heat treatments on the overall mechanical behaviour. This is the main focus of the research detailed in this paper.

Research to date has focussed on either the micro- or the macro-scopic mechanical properties of SLM material, hardness, strength, etc., while little work has examined the nano-scale properties, such as nanohardness. The advantage of using nanoindentation is the very small indentation area and depth of penetration, which are helpful in characterising the local mechanical properties of materials with very fine microstructure, such as SLM AlSi10Mg $[12,18]$. This paper investigates the various mechanical properties of SLM AlSi10Mg at the nano-, micro-, and macroscopic levels. The sub-micron level is represented by the nano-hardness, determined using nanoindentation. To evaluate the strength of the material at the microscopic level, the micro-hardness is measured. Tensile and compressive tests are conducted to reflect the behaviour of the material at the macroscopic level. In this work, the effect of a conventional T6-like procedure on the microstructure and mechanical behaviour at various scales was studied.

\section{MATERIALS AND METHODS}

AlSi10Mg powder supplied by LPW Technology was used to produce near fully dense samples (99.94\% relative density) for the various mechanical tests in this study. The samples were fabricated using a Renishaw AM250 SLM machine equipped with a $200 \mathrm{~W}$ Yb-Fibre laser. The process parameters were $200 \mathrm{~W}$ laser power, a laser scan speed of approximately $570 \mathrm{~mm} / \mathrm{s}$ (achieved by using $80 \mu \mathrm{m}$ point distance and $140 \mu$ s exposure time), $130 \mu \mathrm{m}$ hatch spacing, $25 \mu \mathrm{m}$ layer thickness, and a checkerboard scan strategy (also known as island scanning strategy [18]). Cubic samples $(5 \times 5 \times 5 \mathrm{~mm})$ were produced for nano and micro-hardness tests. Standard dog-bone shaped tensile specimens, following ASTM standard E8/E8M [28], were manufactured with $45 \mathrm{~mm}$ gauge length and $9 \mathrm{~mm}$ gauge diameter. Standard 
cylindrical compression test specimens, following ASTM standard E9 [29], were fabricated then machined by turning to $60 \mathrm{~mm}$ in height and a $20 \mathrm{~mm}$ diameter to ensure the sample had flat parallel ends. Half the samples used in this study were heat-treated following a T6-like procedure by solution heat treatment (SHT) for $1 \mathrm{hr}$ at $520^{\circ} \mathrm{C}$ followed by artificial ageing (AA) for $6 \mathrm{hrs}$ at $160^{\circ} \mathrm{C}$ [27] before testing. The storage time between quenching the samples and starting the ageing process was kept to a minimum $(\sim 0.5-1$ hour $)$.

A MicroMaterials LTD Nanotest NTX Platform3 nanoindenter was used to measure the nano-hardness and indentation modulus of the samples. A Berkovich tip was used for indentation, with the indenter tip shape factor taken into account in the analysis as well as the thermal drift pre- and post-indentation. Tests were performed in accordance with ASTM standard E2546 [30] in a load-controlled mode. The maximum indentation load was set to $7.5 \mathrm{mN}$ and the horizontal (X) and vertical (Y) spacing between adjacent indentations were $10 \mu \mathrm{m}$ and $15 \mu \mathrm{m}$, respectively. The micro-hardness of the samples was measured using a Vickers indenter, applying a load of $3 \mathrm{~N}$ and averaging over 10 indentations per sample. The asbuilt and heat-treated samples were cross-sectioned, polished, and etched using Keller's reagent [31] to reveal the microstructure. A Nikon Eclipse LV100 ND optical microscope was used to image the microstructure. Monotonic uniaxial tension tests were conducted at room temperature using an Instron 5581 universal testing machine equipped with a $50 \mathrm{kN}$ load cell. The tests were carried out in accordance with ASTM standard E8/E8M [28]. The extension rate was $0.5 \mathrm{~mm} / \mathrm{min}$, providing a strain rate of $1.8 \times$ $10^{-4} \mathrm{~s}^{-1}$. A random spatter pattern was applied to the surface of the tensile samples using white and black spray paints in order to aid strain measurement using a video gauge. A Philips XL30 scanning electron microscope (SEM) with a secondary electron detector operating at $20 \mathrm{kV}$ served to examine the fracture surfaces of the samples after tensile tests. The fracture surfaces were also cross-sectioned along the normal plane, polished, and etched to determine the fracture mode and investigate the microstructure in the fractured region. An energy dispersive X-ray (EDX) detector attached to the SEM served to analyse the chemical composition distribution in the fractured region. Uniaxial compression tests were conducted 
at room temperature using an Instron 5985 universal testing machine equipped with a $250 \mathrm{kN}$ load cell. This test was conducted following ASTM standard E9 [29]. The compression was applied at $0.3 \mathrm{~mm} / \mathrm{min}$, resulting in a strain rate of $8.3 \times 10^{-5} \mathrm{~s}^{-1}$ and the test was stopped when the load reached $230 \mathrm{kN}$. Strain data was collected using a linear variable differential transformer (LVDT) because the video gauge was unsuitable for these tests as the samples barrelled sending the pattern out of focus so that the video gauge lost track of the traced spatter pattern.

The results presented in this study are produced from a number of replicates per experiment. Therefore, the reported average values are quoted with standard error. The standard error is calculated by dividing the standard deviation by the square root of the number of readings being averaged.

\section{RESULTS \& DISCUSSION}

\subsection{Nano-mechanical properties}

The average nano-hardness of the as-built SLM material was $1.82 \mathrm{GPa}( \pm 0.01 \mathrm{GPa}$ standard error). After heat treatment, the average nano-hardness was reduced to $1.52 \mathrm{GPa}( \pm 0.02 \mathrm{GPa}$ standard error), showing that the actual effect of heat treatment on the SLM material was one of softening (see Table 1). A t-test was performed to determine the statistical significance of the difference between both data sets with a confidence level of $95 \%$. Since the t-value (12.05) was greater than the critical t-value (1.97) for a twotailed test, the null hypothesis that there is no difference between the as-built and heat-treated nanohardness can be rejected. The nano-hardness maps over the sampled area in the as-built and the heattreated samples are shown in Figure 1 (a) and (b). These maps were developed from arrays comprising 104 indentations each. The as-built material showed a uniform hardness profile whereas the heat-treated material displayed spatial variation within the tested region due to some indentations yielding significantly higher nano-hardness than the average. This was seen in the larger standard deviation in the case of the heat-treated material (0.25) compared to the as-built material (0.13). Examples of the indented regions along with the Berkovich nano-indents are demonstrated in Figure 1 (c) and (d). The uniform 
nano-hardness within the as-built material is attributed to the fine microstructure, with good dispersion of the alloying elements. Inter-dendritic Si can be seen in Figure 2 (a) on the boundaries of $\alpha$-Al. Closer investigation of the microstructure of the as-built material, as shown in Figure 2 (c), revealed that it is made up of $\alpha$-Al columnar grains (dendrites) with $\mathrm{Si}$ segregated at the boundaries. This microstructure is driven by the fast cooling rate that the material experiences during processing [22, 27]. The spatial variation in the nano-hardness of the heat-treated material is due to phase transformation during treatment. The solution heat treatment allows enough time for the segregated Si to diffuse and form particles/spheroids [24, 27], as seen in Figure 2 (b), in addition to microstructural coarsening. The presence of these Si particles, along with the coarser microstructure in terms of larger Si particles and Al grains, produces nano-hardness sensitivity to the indented phase $[32,33]$. The decrease in nano-hardness after heat treatment is attributed to changes in the strengthening mechanisms related to the microstructural changes. The authors [27] have previously compared the strengthening mechanisms in the as-built SLM material to those in the heat-treated material. There are three main factors that are thought to provide the SLM material its strength and these are the ultrafine-grained microstructure (grain boundary strengthening), the alloying elements (solid solution strengthening), and the interaction of dislocations (dislocation strengthening). After heat treatment, the microstructure is no longer ultrafine-grained, as can be seen in Figure 2 (b), reducing the contribution of grain boundaries to strengthening. However, the formation of Si spheroids through spherodisation results in strengthening the material through Orowan strengthening. Therefore, comparing the dislocation motion in the as-built and heat treated material, it can be concluded that motion in the former is mainly limited by the increased volume of grain boundaries and in the latter through obstruction by the Si spheroids. The higher nano-hardness in the as-built material suggests that the strengthening effect of the fine microstructure, characteristic of SLM Al alloys, is more than that achieved by solution heat treatment and ageing that leads to spherodisation transformation. The indentation modulus of the as-built samples was $100 \pm 1 \mathrm{GPa}$ and that of the heat-treated samples was 105 $\pm 1 \mathrm{GPa}$. Further discussion of this effect is presented in the tensile properties section. 
Table 1: Comparing the hardness of SLM AISi10Mg with and without heat treatment

\section{SLM AlSi10Mg}

Nano-hardness (GPa)

Vickers hardness (HV)
Heat-treated (T6) (1 hr SHT + 6 hrs AA)
Heat-treated (T6) (6 hrs SHT + 7 hrs AA) (a)

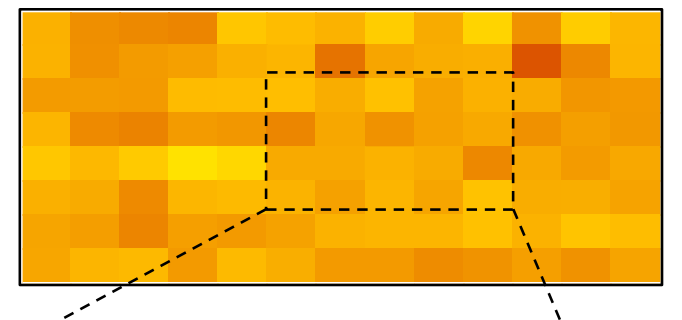

(c)

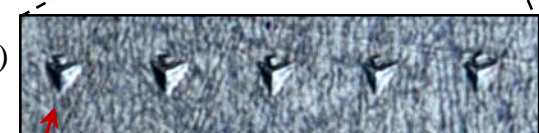

$1.82 \pm 0.01$

$125 \pm 1$
$1.52 \pm 0.02$

$100 \pm 1$
$103 \pm 2$ (b)

(d)
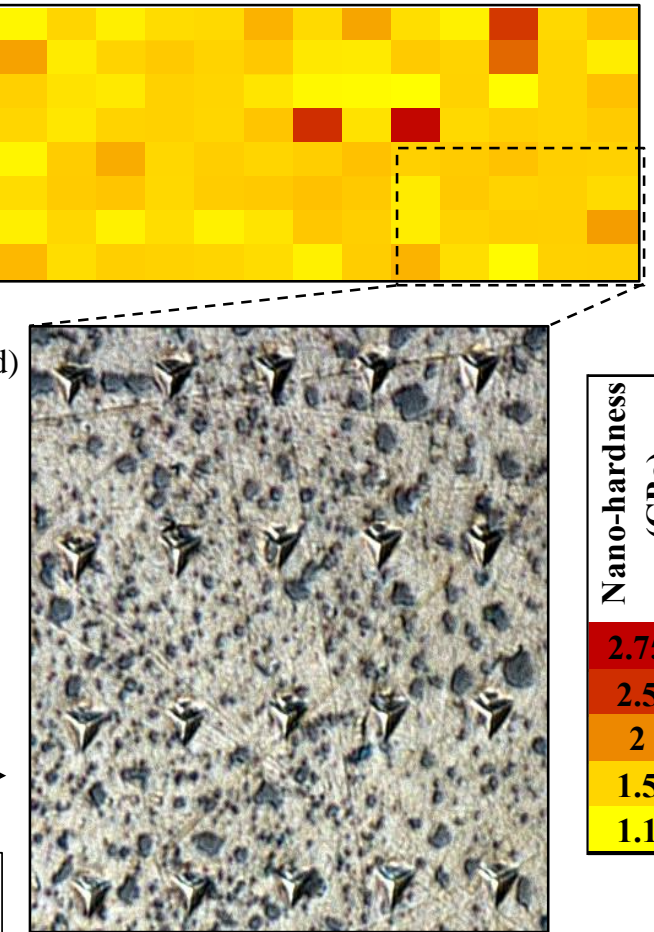

Figure 1: Nano-hardness map demonstrating the property profile within (a) as-built SLM AISi10Mg and (b) heat-treated SLM AISi10Mg, as well as optical micrographs showing examples of the nano-indents on the tested surfaces (c) as-built material and (d) heat-treated material. 


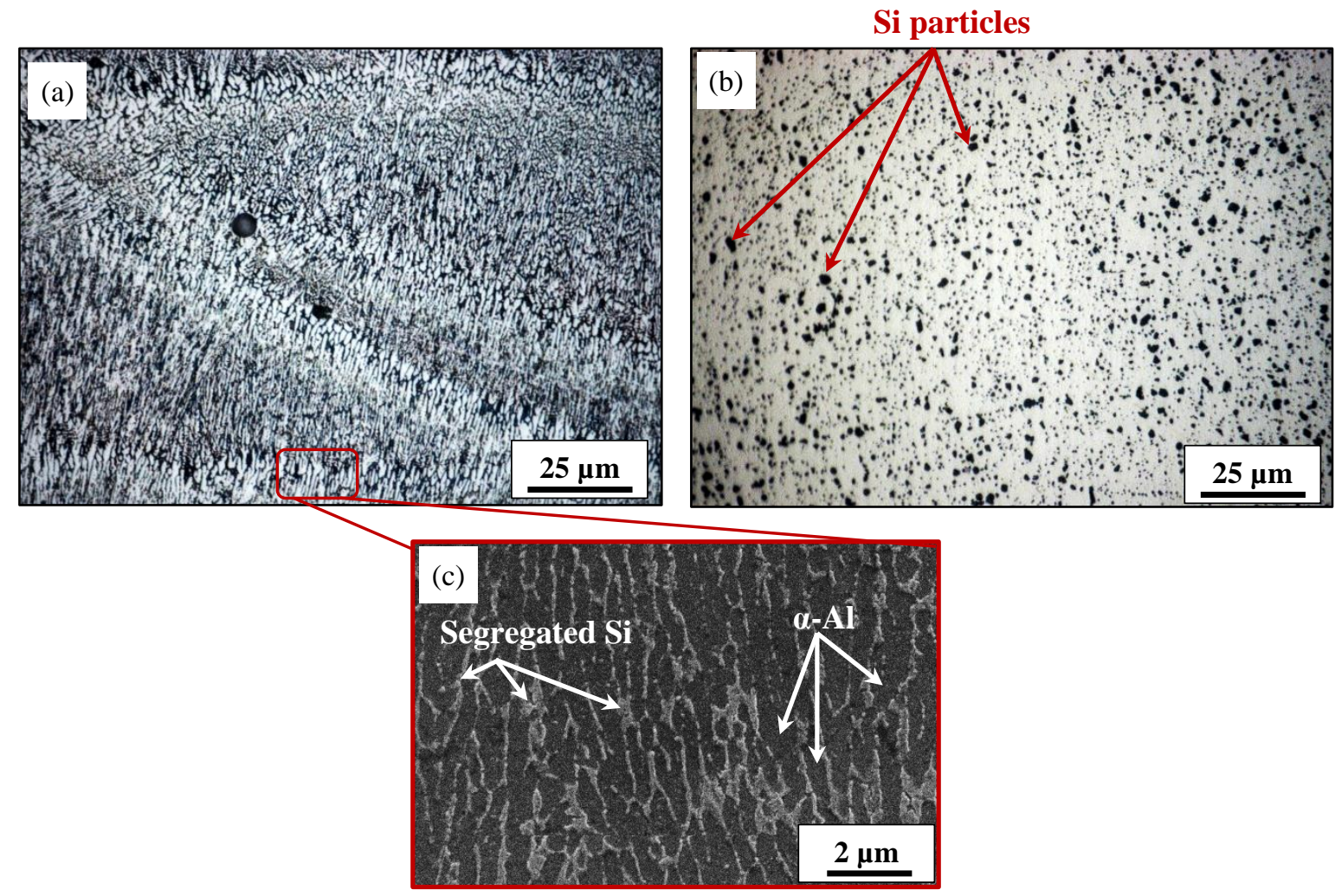

Figure 2: Microstructure of the SLM AISi10Mg (a) as-built and (b) heat-treated as seen by optical microscopy, and (c) high magnification SEM image for the as-built microstructure revealing Si segregated on the boundaries of $\alpha$-Al.

\subsection{Micro-mechanical properties}

The overall micro-hardness, provided in Table 1, shows the same trend as the nano-hardness results. The hardness of the as-built material was reduced by nearly $20 \%$ after heat treatment, indicating material softening. This agrees with earlier results by the authors [27] that reported material softening rather than hardening when using a T6-like heat treatment with SLM AlSi10Mg. Although Al-Si-Mg alloys are capable of precipitating $\mathrm{Mg}_{2} \mathrm{Si}$ through solution heat treatment and artificial ageing [34], which is responsible for the hardening effect for which the T6 heat treatment procedure is used (often referred to as precipitation hardening) [27], it is not clear whether precipitation occurred during the current treatment. During precipitation hardening of conventionally cast Al-Si alloys, a super saturated solid solution is developed in the solution heat treatment stage, which is maintained by rapid quenching. The metallic compound $\mathrm{Mg}_{2} \mathrm{Si}$ and Guinier-Preston I (GP I) zones form at early stages of ageing. Then Guinier-Preston II (GP II) zones form at regions containing metallic compounds rather than the solid solution with further 
ageing [35]. Following the formation of GP II zones (in the form of rods), a $\beta$ ' intermetallic phase is formed (also in the form of rods or needle-like structures), which is followed by the intermetallic phase at equilibrium that is $\beta$-phase " $\mathrm{Mg}_{2} \mathrm{Si}$ " (in the form of plates) [36]. The metallurgical aspect of what actually happens during this heat treatment, in terms of microstructural modification and phase transformation and whether $\mathrm{Mg}_{2} \mathrm{Si}$ is precipitated during heat treating the SLM material requires further investigation. The effect of a T6-like procedure with prolonged durations (e.g. solution heat treatment for $6 \mathrm{hrs}$ and ageing for $7 \mathrm{hrs}$ ) has been used in a number of studies, in which it was referred to as peak hardening [25, 37]. This prolonged procedure was also investigated in this study for micro-hardness only, however still no hardening effect was noticeable, where the micro-hardness of the SLM material was reduced to $103 \pm 2 \mathrm{HV}$ following T6-like treatment. This is further evidence that the SLM material responds to the T6-like heat treatment by softening. The micro-hardness of the as-built SLM material was higher than its die cast counterpart (95-105 HV [21]), however, a T6 heat treatment for the die cast material increased the micro-hardness to 130-133 HV [21], to become comparable to that of the as-built SLM material. The difference in the response of the as-built SLM material from that of the conventionally cast material to T6-like heat treatment is driven by the characteristically fine microstructure developed by SLM when processing AlSi10Mg. Leuder et al. [38] stated that SLM generally produces microstructures different from those developed when using conventional processes, leading to the need for some adjustments to the conventional heat treatment procedures.

The average hardness retrieved from nano-indentation is significantly higher than that determined in micro-hardness testing, which is an intrinsic size effect. Zong et al. [39] observed an increase in hardness value as the depth of indentation shifted from the micron to the nano scale. For the as-built material, the average micro-hardness was $1.23 \mathrm{GPa}$, less than the nano-hardness by almost $33 \%$. Similarly, the average micro-hardness of the heat-treated material (0.98 GPa) was nearly 36\% less than its nano-hardness. Nanoindentation hardness has been previously reported to be typically $10-30 \%$ less than the microhardness for a range of materials [40] due to assuming a purely elastic contact and using the projected 
contact area in the data analysis in nanoindentation instead of the residual projected area. The projected contact area is smaller than the residual projected area whether the material piles-up or sinks-in under indentation loading [41].

\subsection{Macro-mechanical properties}

The engineering stress-strain curves in Figure 3 show that the as-built samples behave in a relatively brittle fashion under tensile loading. However, it can be seen that the heat treatment provided the material with enhanced ductility without a drastic sacrifice in tensile strength, as demonstrated by the extension in the plastic deformation region in the stress-strain curve. It is hard to categorise a material as ductile or brittle based on the elongation percent only [41], therefore, the macroscopic features on the fracture surface were examined. Fractography revealed that failure always originated at a surface or sub-surface flaw, as shown in the inset in Figure 3. This could be attributed to the poor surface roughness, which is common in SLM parts, and/or the presence of sub-surface defects, such as pores or laser spatter [42]. Macroscopically, the fracture surface was flat with a few regions showing shear lips, which is a sign of brittle failure [41]. No significant necking was observed in any of the tested samples due to the processinduced brittleness. This was also demonstrated by the fracture stress being equal to the ultimate tensile strength. The fine fracture features in the as-built samples are shown in Figure 4 (a); these fracture features coarsen after heat treatment, as seen in the dimpled surface in Figure 4 (b). Shallow dimples are seen on the surface of the as-built material (Figure 4 (a)) indicating failure in a brittle mode [40]. Equiaxed dimples are clearly seen in the heat-treated sample (Figure 4 (b)) indicating micro-void coalescence and deformation by slip [41], which is a ductile failure feature [43]. The failure mechanism is better understood from the cross-sectional views of the fracture surfaces provided in Figure 5. In the asbuilt material (Figure $5(\mathrm{a})$ ), the crack propagates along the interface between the melt pool core and boundary, which was consistent along the fracture surfaces. This is because the melt pool boundary is softer than the melt pool core, having a coarser microstructure and less Si content for the reduced grain boundary area. For the heat-treated material (Figure 5 (c)), voids nucleate at the Si particles by de- 
cohesion [44] then void coalescence occurs and cracks propagate until complete separation occurs and the sample fails under tensile loading. The chemical distribution of the elements in the alloy (mapped in Figure 5 (b) and (d)) confirms the scenario of the transformation of the Si segregating into randomly distributed spheroids with heat treatment as well as microstructural coarsening.

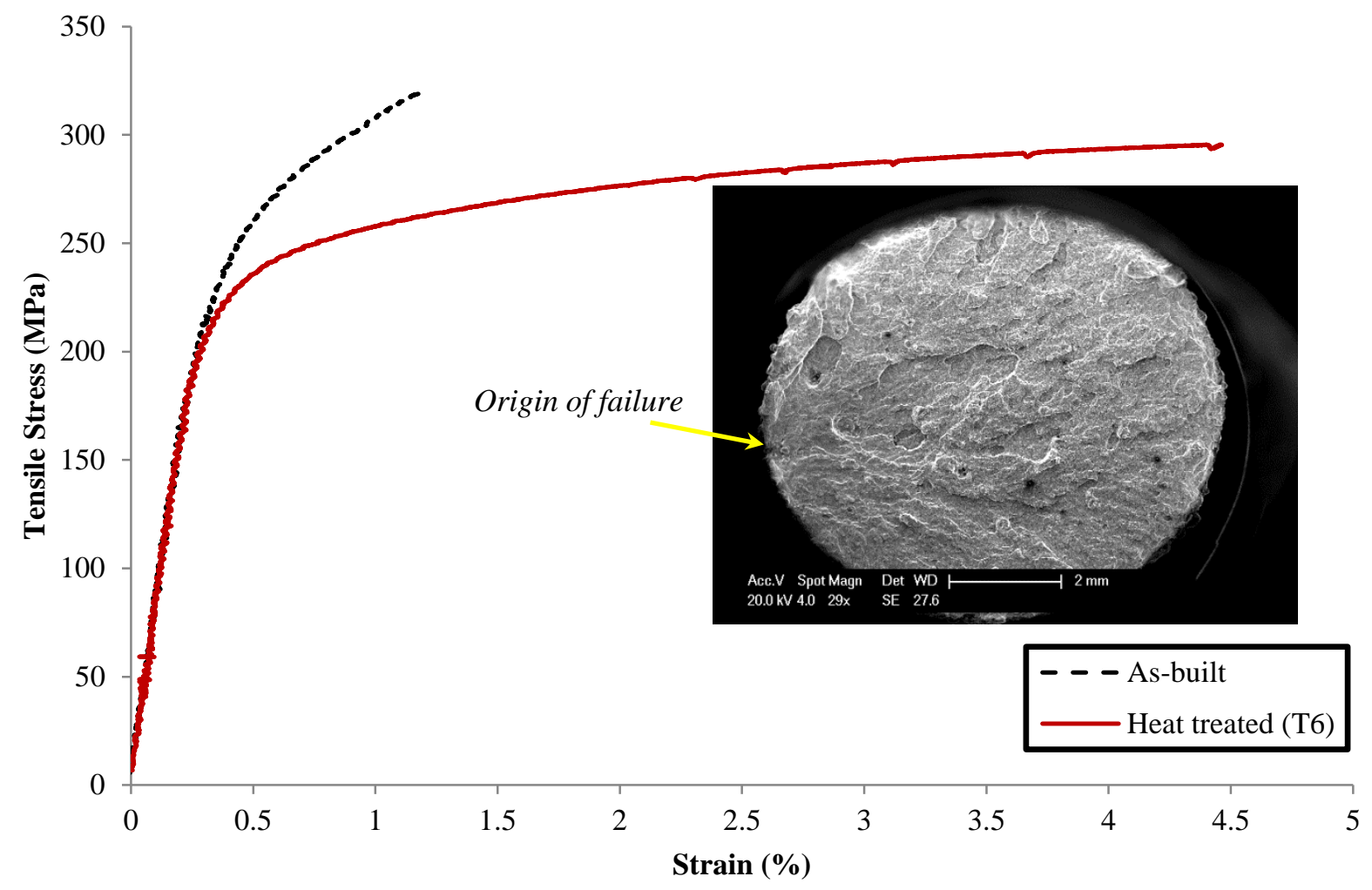

Figure 3: Engineering tensile stress-strain curves comparing the behaviour of SLM AISi10Mg with and without heat treatment. The inset shows SEM image for the fracture surface with failure originating at a surface defect in an as-built sample. 

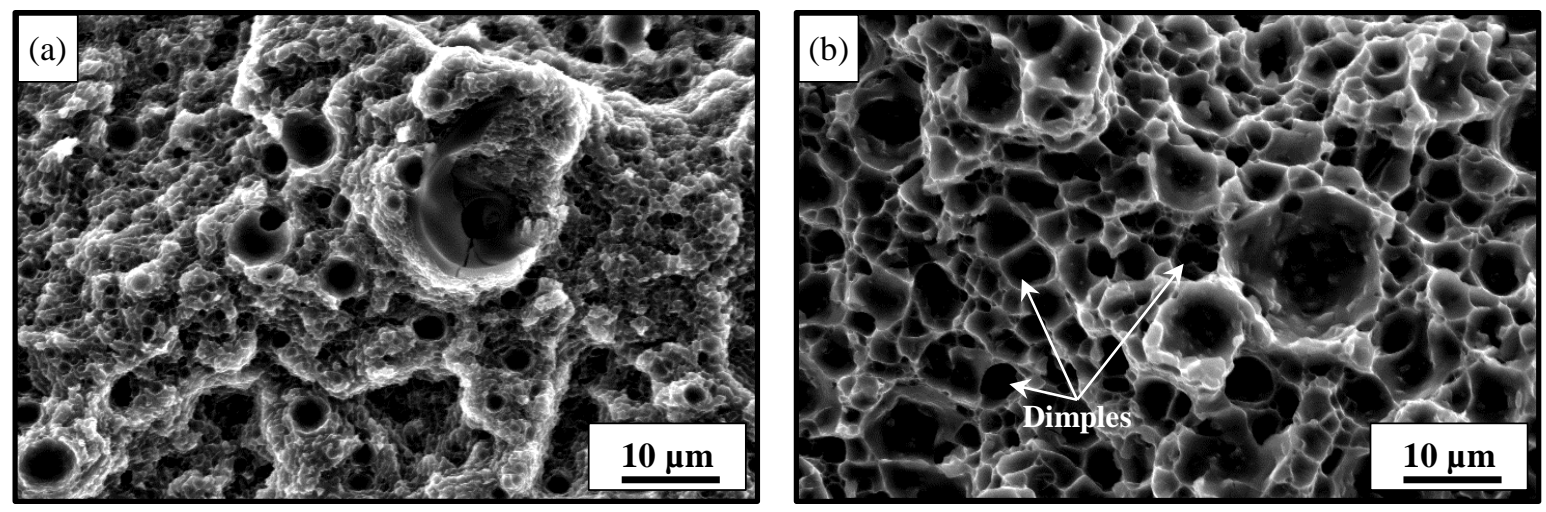

Figure 4: SEM images for the fracture surface of SLM AlSi10Mg (a) as-built and (b) heat treated.
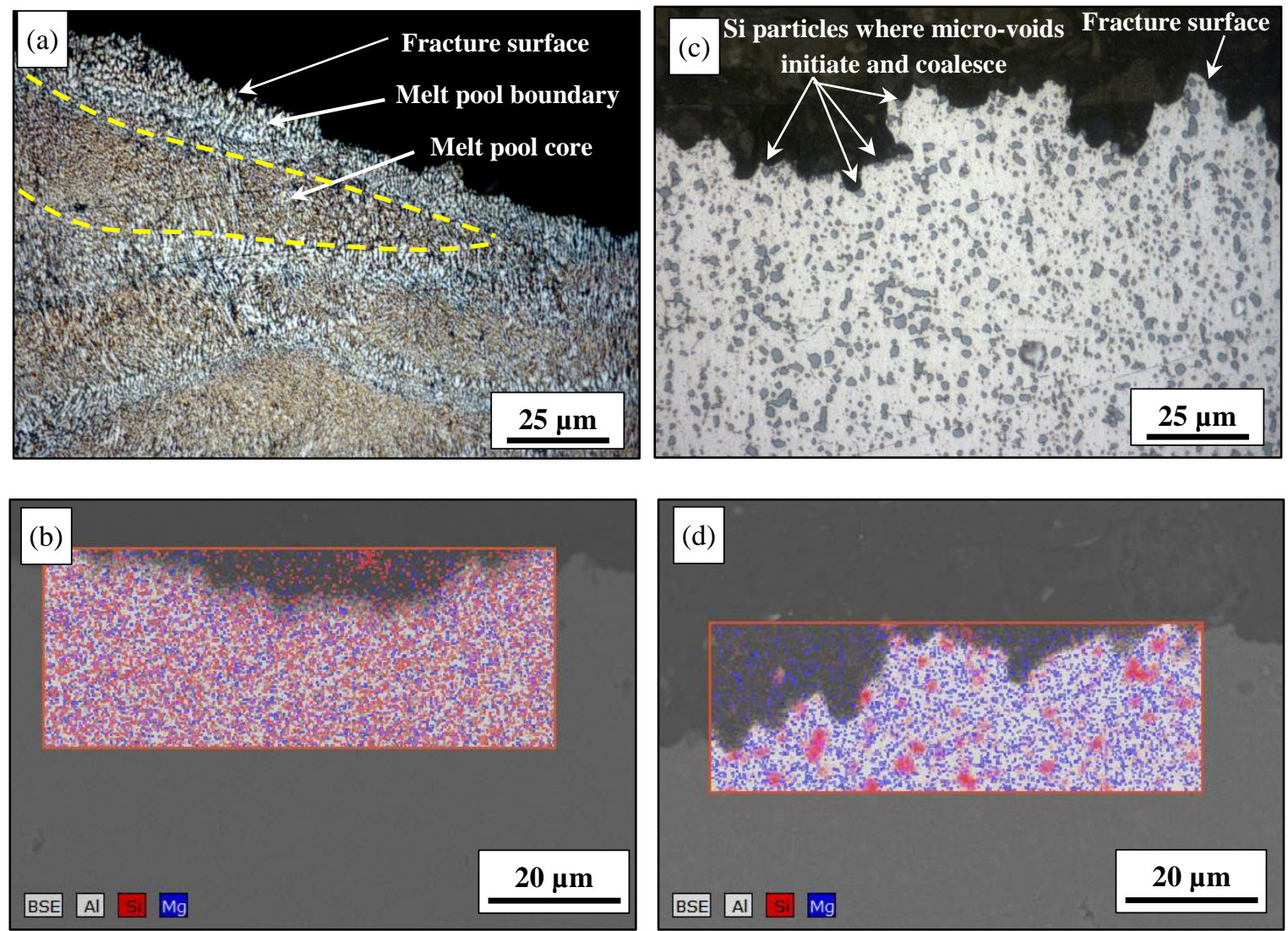

Figure 5: Cross-sectioned fracture surface of tensile samples. (a) optical micrograph for the as-built material showing the crack propagating along the melt pool boundary causing detachment of the melt pool core above, with a representative chemical composition mapping in the SEM image in (b). (c) optical micrograph of the heat-treated material showing crack propagation by void coalescence along $\mathrm{Si}$ particles with the chemical composition mapped in the SEM image in (d).

The overall tensile properties of the samples with and without heat treatment can be found in Table 2. The decrease in the material's ultimate tensile strength, yield strength, and elastic modulus after heat treatment is attributed to microstructural coarsening, as determined by the microscopic investigation, which shows a 
reduction in the grain boundary area that acts as a barrier for the motion of dislocations during deformation. Heat treatment reduced the ultimate tensile strength by almost $12 \%$, whilst increasing the ductility by a factor of 2.8. These results are an enhancement in the tensile behaviour of SLM AlSi10Mg with respect to the literature for this alloy [19]. The tensile strength of SLM AlSi10Mg exceeds that of the A360 die cast material, which is the most comparable alloy to the AlSi10Mg, but the former has lower ductility. However, the ductility of the SLM material was improved by heat treatment, making it more suitable for applications that require higher ductility capabilities as a design consideration. This shows that the T6-like heat treatment yielded a potentially attractive compromise between the material's ductility and strength. The moduli of elasticity determined from tensile tests (Table 2) were less than those determined using nanoindentation, which were $100 \pm 1 \mathrm{GPa}$ and $105 \pm 1 \mathrm{GPa}$ for the as-built and heat-treated materials, respectively. The variation between absolute values of properties measured from the tension tests and nanoindentation is commonly seen [45]. Similar to the case of comparing the nanohardness to the micro-hardness, this is also explained by the fact that the sampling area in nanoindentation is extremely small, as is the depth of penetration into the material. Nano-indentation determines the local mechanical properties of the material meaning that nanoindentation would not detect the defects within the part, and hence the indentation modulus is usually higher than that determined by the behaviour of the material at the macroscopic level.

Table 2: Tensile properties of SLM AISi10Mg developed in this study compared to results from the literature for SLM and die cast counterparts.

\begin{tabular}{ccccc}
\hline Sample & $\begin{array}{c}\text { Yield tensile strength } \\
\text { at } 0.2 \% \text { offset }(\mathrm{MPa})\end{array}$ & $\begin{array}{c}\text { Tensile Modulus } \\
(\mathrm{GPa})\end{array}$ & $\begin{array}{c}\text { Ultimate Tensile } \\
\text { Strength }(\mathrm{MPa})\end{array}$ & Elongation (\%) \\
\hline SLM - As-built & $268 \pm 2$ & $77 \pm 5$ & $333 \pm 15$ & $1.4 \pm 0.3$ \\
SLM - Heat treated T6 & $239 \pm 2$ & $73 \pm 4$ & $292 \pm 4$ & $3.9 \pm 0.5$ \\
SLM - Read et al. ${ }^{[19] 2}$ & $\sim 231 \pm 10$ & - & $\sim 316 \pm 43$ & $\sim 1.1 \pm 0.4$ \\
Die cast -A360 ${ }^{[46]}$ & 175 & - & 320 & 3.0 \\
\hline
\end{tabular}

\footnotetext{
${ }^{2}$ Data presented here are approximate values collected from bar charts in the original publication.
} 
The compressive behaviour is presented in Figure 6. Neither the as-built nor the heat-treated samples fractured under compressive loading up to $230 \mathrm{kN}(\sim 700 \mathrm{MPa})$. The inset in Figure 6 shows the samples before and after testing with barrelling and buckling clearly observed in the tested samples. Generally, barrelling in $\mathrm{Al}$ samples under compressive loading is quite common due to heterogeneous deformation, where the material at the top and bottom surfaces is constrained by friction with the test rig and the rest of the sample experiences high strain hardening and flows forming a barrel [47]. The general compressive properties are listed in Table 3. Heat treatment has significantly reduced the yield compressive strength of the material, by $\sim 150 \mathrm{MPa}$. It is worth noting that the yield strengths of the as-built and heat-treated materials were much higher than the cast equivalent, which is approximately $100 \mathrm{MPa}$ [48]. Both the ultimate compressive strength and strain at fracture were not determined in these experiments due to limitations on the capacity of the load cell used in testing.

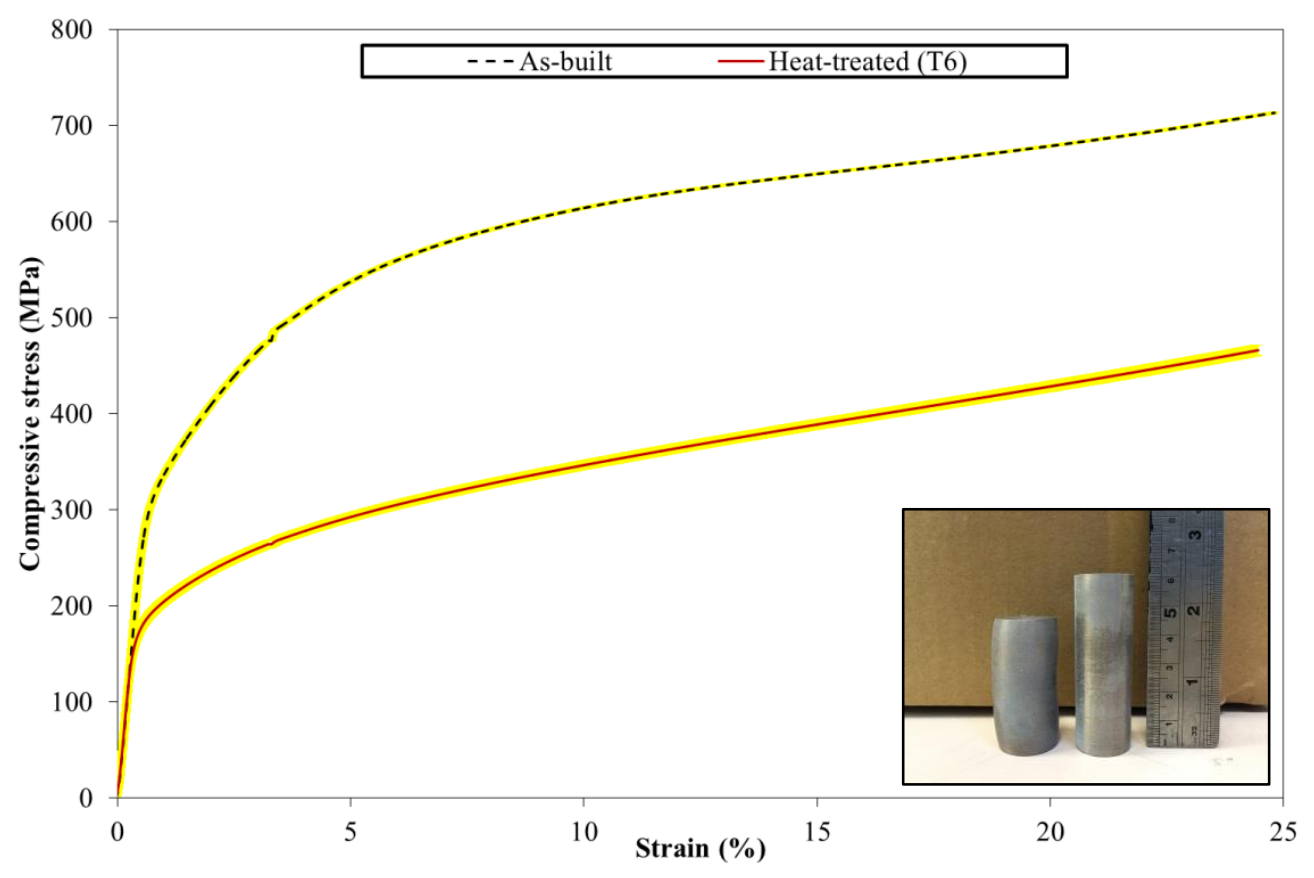

Figure 6: The compressive behaviour of SLM AISi10Mg with and without heat treatment (average of three results per condition). The standard error is highlighted in yellow. The inset showing samples before and after testing. 
Table 3: Compressive properties of SLM AISi10Mg.

\begin{tabular}{ccc|}
\hline Condition & $\begin{array}{c}\text { Yield compressive } \\
\text { strength }(\mathrm{MPa})\end{array}$ & $\begin{array}{c}\text { Compressive strength at } \\
25 \% \text { strain }(\mathrm{MPa})\end{array}$ \\
\hline As-built & $317 \pm 2$ & $714 \pm 1$ \\
Heat treated T6 & $169 \pm 6$ & $466 \pm 6$ \\
\hline
\end{tabular}

Fractographs of tensile tests showed the presence of surface or sub-surface pores to be the origin of failure indicating that regions of porosity are susceptible to failure under tensile loading. In the case of compressive loading, porosity was not seen to be critical. This is because the nature of loading tends to close the pores, consolidating the defected regions, as long as porosity is minimal. In contrast, under tensile loading, pores start to stretch, coalesce, and propagate in the form of cracks that lead to failure.

\section{SUMMARY \& CONCLUSIONS}

Selectively laser melted AlSi10Mg was evaluated for a number of mechanical properties and the influence of a conventional T6-like heat treatment on these properties was determined. A summary of the effect of heat treatment on the various mechanical properties can be found in Table 4. The interrelation between the mechanical behaviour and the microstructural features was developed. The as-built material showed uniform nano-hardness within the material because of the extremely fine microstructure and the homogenous distribution of the alloying elements. Variation in the nano-hardness across the material was observed after heat treatment due to the change in microstructure, i.e. the diffusion of the well-dispersed Si to form coarser particles (spheroids large enough to be detected by nano-indentation and develop sensitivity to the indented phases). This study reported a high micro-hardness for the SLM material, surpassing the die-cast counterpart and comparable to the hardened die-cast. Both nano- and microhardness tests showed material softening upon heat treatment, a finding that opposes the behaviour of conventionally manufactured Al-Si alloys that normally show a hardening effect with this heat treatment. This is attributed to the difference in the starting microstructures. The ultimate and yield tensile strengths of the as-built SLM material were considerably higher than the die-cast counterpart, but the material also 
exhibited poor elongation to failure. However, the ductility was significantly enhanced by the heat treatment, maintaining the high yield strength of the SLM material compared to the die-cast counterpart, with only a small reduction in ultimate tensile strength. It is important to note that the reduction in strength with heat treatment was small compared to the relatively large gain in elongation to failure. Both the as-built and heat-treated materials demonstrated the ability to withstand high compressive strains as they barrelled and buckled during compression with no evidence of fracture. Heat treatment resulted in reducing the compressive yield strength of the material but it still remained higher than the cast equivalent.

Table 4: Summary of the effect of a conventional T6 heat treatment on mechanical performance of SLM AISi10Mg. The change in mechanical properties is quantified and presented as a percentage.

\begin{tabular}{cc} 
Property & Effect of heat treatment (\%) \\
\hline Nano-hardness & $-(16 \pm 1) \downarrow$ \\
Micro-hardness & $-(20 \pm 1) \downarrow$ \\
Ultimate tensile strength & $-(12 \pm 5) \downarrow$ \\
Yield tensile strength & $-(11 \pm 1) \downarrow$ \\
Tensile elongation at failure & $+(179 \pm 57) \uparrow$ \\
Compressive strength at 25\% strain & $-(56 \pm 0.003) \downarrow$ \\
Yield compressive strength & $-(47 \pm 2) \downarrow$ \\
\hline
\end{tabular}

This study reported the mechanical properties of SLM AlSi10Mg at the nano-, micro-, and macro-scopic levels and correlated them to the material's microstructure. These results show that the characteristic microstructure produced during SLM yields improved mechanical properties compared to conventionally processed material considering a wide range of properties at various levels. The work here also underpins a misconception that SLM AlSi10Mg alloy is hardenable using T6 heat treatment since the findings in this study showed the distinct starting microstructure led to softening using this heat treatment rather than hardening, improving the material's ductility without a significant decrease in strength. This demonstrates the need for a new set of heat treatment procedures to be designed and tailored specifically 
for SLM materials and the desired mechanical properties. In combination with the design freedom of SLM, this work can be used to deliver parts with a range of previously unachievable mechanical properties.

\section{ACKNOWLEDGMENTS}

Nesma T. Aboulkhair gratefully acknowledges funding provided by the Dean of Engineering Scholarship for International Research Excellence, Faculty of Engineering, University of Nottingham, United Kingdom. Thanks to Mr. Mark Hardy, Mr. Tom Buss, and Mr. Jason Greaves for their help with samples preparation and testing.

\section{REFERENCES}

[1] A. Aremu, I. Ashcroft, R. Wildman, R. Hague, C. Tuck, D. Brackett, Proceedings of the Institution of Mechanical Engineers, Part B: Journal of Engineering Manufacture, (2013).

[2] N. Gardan, International Journal of Manufacturing Engineering, 2014 (2014) 9.

[3] J. Brennan-Craddock, D. Brackett, R. Wildman, R. Hague, in, Journal of Physics: Conference series, 2012.

[4] D.J. Brackett, I.A. Ashcroft, R.D. Wildman, R.J.M. Hague, Computers \& Structures, 138 (2014) 102111.

[5] C. Yan, L. Hao, A. Hussein, P. Young, D. Raymont, Materials \& Design, 55 (2014) 533-541.

[6] P. Edwards, M. Ramulu, Materials Science and Engineering: A, 598 (2014) 327-337.

[7] M. Baumers, C. Tuck, R. Hague, I. Ashcroft, R. Wildman, in: 21st Annual International Solid Freeform Fabrication Symposium - An Additive Manufacturing Conference, SFF 2010, 2010, pp. 278288.

[8] A. Gebhardt, F.-M. Schmidt, J.-S. Hötter, W. Sokalla, P. Sokalla, Physics Procedia, 5, Part B (2010) 543-549.

[9] H.A. Macleod, Thin Film Optical Filters, 3rd edition ed., CRC Press, United Kingdom, 2001. 
[10] ASM, ASM Metals Reference Book, 3rd edition ed., ASM International, United States of America, 1993.

[11] K. Kempen, L. Thijs, J. Van Humbeeck, J.P. Kruth, Materials Science and Technology, 31 (2014) 917-923.

[12] N.T. Aboulkhair, N.M. Everitt, I. Ashcroft, C. Tuck, Additive Manufacturing, 1-4 (2014) 77-86.

[13] S. Dadbakhsh, L. Hao, P.G.E. Jerrard, D.Z. Zhang, Powder Technology, 231 (2012) 112-121.

[14] D. Buchbinder, H. Schleifenbaum, S. Heidrich, W. Meiners, J. Bültmann, Physics Procedia, 12, Part A (2011) 271-278.

[15] E. Louvis, P. Fox, C.J. Sutcliffe, Journal of Materials Processing Technology, 211 (2011) 275-284.

[16] E.O. Olakanmi, Journal of Materials Processing Technology, 213 (2013) 1387-1405.

[17] C. Weingarten, D. Buchbinder, N. Pirch, W. Meiners, K. Wissenbach, R. Poprawe, Journal of Materials Processing Technology, 221 (2015) 112-120.

[18] L. Thijs, K. Kempen, J.-P. Kruth, J. Van Humbeeck, Acta Materialia, 61 (2013) 1809-1819.

[19] N. Read, W. Wang, K. Essa, M.M. Attallah, Materials \& Design, 65 (2015) 417-424.

[20] M. Simonelli, Y.Y. Tse, C. Tuck, Materials Science and Engineering: A, 616 (2014) 1-11.

[21] K. Kempen, L. Thijs, J. Van Humbeeck, J.P. Kruth, Physics Procedia, 39 (2012) 439-446.

[22] S. Siddique, M. Imran, E. Wycisk, C. Emmelmann, F. Walther, Journal of Materials Processing Technology, 221 (2015) 205-213.

[23] X.J. Wang, L.C. Zhang, M.H. Fang, T.B. Sercombe, Materials Science and Engineering: A, 597 (2014) 370-375.

[24] K.G. Prashanth, S. Scudino, H.J. Klauss, K.B. Surreddi, L. Löber, Z. Wang, A.K. Chaubey, U. Kühn, J. Eckert, Materials Science and Engineering: A, 590 (2014) 153-160.

[25] E. Brandl, U. Heckenberger, V. Holzinger, D. Buchbinder, Materials \& Design, 34 (2012) 159-169.

[26] C. Qiu, S. Yue, N.J.E. Adkins, M. Ward, H. Hassanin, P.D. Lee, P.J. Withers, M.M. Attallah, Materials Science and Engineering: A, 628 (2015) 188-197. 
[27] N.T. Aboulkhair, C. Tuck, I. Ashcroft, I. Maskery, N.M. Everitt, Metall Mater Trans A, 46A (2015) 3337-3341.

[28] ASTM E8 / E8M-15a, Standard Test Methods for Tension Testing of Metallic Materials, ASTM International, West Conshohocken, PA, 2015, www.astm.org

[29] ASTM E9-09, Standard Test Methods of Compression Testing of Metallic Materials at Room

Temperature, ASTM International, West Conshohocken, PA, 2009, www.astm.org

[30] ASTM E2546-15, Standard Practice for Instrumented Indentation Testing, ASTM International, West Conshohocken, PA, 2015, www.astm.org

[31] G.F.V. Voort, Metallography: Principles \& practice, ASM International United States of America, 1999.

[32] N.T. Aboulkhair, I. Maskery, C. Tuck, I. Ashcroft, N.M. Everitt, in: 4th UK Industrial Laser Applications Symposium, SPIE, Kenilworth, UK, 2015.

[33] N.T. Aboulkhair, I. Maskery, C. Tuck, I. Ashcroft, N.M. Everitt, Journal of Materials Processing Technology, 230 (2016) 88-98.

[34] W. Li, S. Li, J. Liu, A. Zhang, Y. Zhou, Q. Wei, C. Yan, Y. Shi, Effect of heat treatment on AlSi10Mg alloy fabricated by selective laser melting: Microstructure evolution, mechanical properties and fracture mechanism, Materials Science and Engineering: A 663 (2016) 116-125.

[35] M. Tisza, Physical metallurgy for engineers, ASM International and Fruend Publishing House Ltd., 2002.

[36] D.A. Porter, K.E. Easterling, Phase transformation in metals and alloys, Chapman \& Hall, Great Britain, 1992.

[37] D. Buchbinder, W. Meiners, K. Wissenbach, K. Müller-Lohmeier, E. Brandl, in: International Conference on Rapid Manufacturing, Loughborough University, 2009.

[38] S. Leuders, M. Thöne, A. Riemer, T. Niendorf, T. Tröster, H.A. Richard, H.J. Maier, International Journal of Fatigue, 48 (2013) 300-307. 
[39] Z. Zong, J. Lou, O.O. Adewoye, A.A. Elmustafa, F. Hammad, W.O. Soboyejo, Materials Science and Engineering: A, 434 (2006) 178-187.

[40] L. Qian, M. Li, Z. Zhou, H. Yang, X. Shi, Surface and Coatings Technology, 195 (2005) 264-271.

[41] Charlie R. Brooks, A. Choudhury, Failure analysis of engineering materials, McGraw-Hill, United states of America, 2002.

[42] M. Simonelli, C. Tuck, N.T. Aboulkhair, I. Maskery, I. Ashcroft, R.D. Wildman, R. Hague, Metall Mater Trans A, 46A (2015) 3842-3851.

[43] J. C. McMillan, R. W. Hertzberg, Application of electron fractography to fatigue studies, American Society for Testing and Materials, New Jersey, 1968.

[44] T. Tinga, Principles of Loads and Failure mechanisms: Applications in Maintenance, Reliability and Design, H. Pham (Ed), Springer, 2013.

[45] E. Harvey, L. Ladani, M. Weaver, Mechanics of Materials, 52 (2012) 1-11.

[46] Properties of aluminum alloys tensile creep and fatigue data at high and low temperatures, ASM International Materials Park, Ohio, 1999.

[47] R. Narayanasamy, K.S. Pandey, Journal of Materials Processing Technology, 70 (1997) 17-21.

[48] M. Kiser, M.Y. He, F.W. Zok, Acta Materialia, 47 (1999) 2685-2694. 